\title{
EL TEATRE MUSICAL D’ÀNGEL GUIMERÀ
}

\author{
MARIDÉS SOLER \\ (vorm. Universität Trier) \\ marides-s@gmx.de \\ Recibido: noviembre de 2013. Aceptado: diciembre de 2013
}

Resum: Les relacions entre la literatura i la música poden considerar-se com una secció de la literatura comparada, ja que es tracta de dues arts similars basades sobretot en el ritme i les imatges. En el cas concret del teatre musical, la llibretologia, un subgènere literari menystingut sense raó, hi juga un paper predominant. Ja des dels inicis de la seva carrera com a dramaturg, Guimerà va procurar introduir música en les seves obres mantenint intensos contactes amb els principals compositors de l'època (Morera, Vives i Pahissa); al principi només van ser tímides mostres de música incidental, a continuació van seguir, d'acord amb els cànons modernistes de l'època, «espectacles musicals», on es presentaven cants i balls junt amb escenografies espectaculars, per acabar escrivint ell mateix els llibrets. En vida van representar-se a més quatre òperes a l'estranger basades en les seves obres i el 1988 en ocasió del centenari de Mar i cel va estrenar-se el musical homònim.

Mots clau: Guimerà, Àngel, teatre musical - Guimerà, Àngel, òperes - Teatre musical català - Les monges de Sant Aimant - Euda d'Uriac - La santa espi$n a-$ La reina vella - Titaina - Tiefland - Liebesketten-Mar i cel

\begin{abstract}
The relations between literature and music may be considered as a section of comparative literature, as both are similar arts based especially in the rhythm and the images. In the specific case of music theatre, the librettology, a literary subgenre wrongly underrated, plays also a mainly role. Already from beginning his career as playwriter, Guimerà always tried to introduce music in his plays and looked for close contact with the main composers of his time (Morera, Vives and Pahissa); firstly were only shy attempts of incidental music, afterwards followed «musical shows» according to the Modernist rules of the epoch, which prescribed songs and dancing embedded in spectacular scenographies, and finally he wrote himself the libretti. In his lifetime four operas set up on his plays were played abroad and 1988 in occasion of the centenary of Mar i cel took also place the premiere of the homonym musical.
\end{abstract}

Keywords: Guimerà, Àngel, music theatre - Guimerà, Àngel, operas - Catalan music theatre - Les monges de Sant Aimant - Euda d'Uriac - La santa espina - La reina vella - Titaina - Tiefland - Liebesketten - Mar i cel. 


\section{LITERATURA I MÚSICA}

\subsection{Història}

Originàriament només existia la música vocal, és a dir text acompanyat de música, i tant Plató com Aristòtil veien ambdues arts com una unitat, si bé postulaven que la lletra tenia més importància que la música. ${ }^{1}$ Els primers intents per conferir una forma artística a la música vocal va començar fa uns 400 anys enrera amb les òperes de Monterverdi i Händel, en les quals el text predominava sobre la música, segons la fòrmula: «prima le parole e dopo la musica», la qual aviat va ser tergiversada en: «prima la musica e dopo le parole». Gluck mantenia en el seu pròleg d'Alceste (1767) que calia que la música servís de nou a la lletra sense interrompre l'acció i sense carregar-la d'ornaments superflus (Schueller 1984: 69). No obstant això, a partir de Mozart la música domina sense discussió la lletra i no serà fins arribar a Wagner, ${ }^{2}$ que el text i la música són de nou paritaris tenint llur culminació en Capriccio de R. Strauss, la qual versa de nou sobre la preponderància entre música i text trenada en una «conversació» elegant i sofisticada. Tanmateix la història ha demostrat que, de fet, gairebé sempre una òpera serà famosa a causa de la música i no de la lletra, ja que òperes amb llibrets desgavellats, però amb música interessant han tingut èxit, per exemple Lucia de Lammermoor o Rigoletto i no al revés, si bé un llibret fluix també pot perjudicar indirectament el desenvolupament de l'acció.

\subsection{Interrelacions música-literatura}

L'estudi de les relacions de la literatura i la música poden incloure's dins la literatura comparada, ja que es tracta de dues arts similars basades en el ritme i les imatges. La combinació d'aquestes dues arts van des de la música vocal passant per la música de fons i incidental fins arribar a la recitació d'obres literàries. La seva investigació pot enfocar-se des de tres perspectives (Scher 1984: 11-14):

1.2.1 Literatura i música: es tracta de les relacions entre composició musical i text literari (òpera, lied, oratori, cantata), és a dir el que s'entén per música vocal. Dins aquest apartat cal considerar també la llibretologia. Els llibrets, l'existència dels quals data d'uns 400 anys (Gier 1986: 5), han gaudit gairebé sempre d'una posició subalterna en comparació amb la música. ${ }^{3}$ Tanmateix, cal

${ }^{1}$ La literatura va ser la primera que va independitzar-se de la música: mentre la Ilíada només era cantada, ja l'Eneida va estar concebuda per a ser declamada, tot i que a Grècia es practicava també la música instrumental pura (Brown 1984: 28).

2 Wagner és considerat un geni amb «Doppelbegabung», és a dir amb talent doble, el qual alia una simbiosi de diferents arts. E. d'Albert, el compositor de Tiefland (Terra baixa), gran admirador de Wagner, també ho va provar, peró va desdir-se aviat per trobar impossible reeixir amb èxit escriure alhora text i música (Pangels 1981: 391).

3 Al llarg de la història de l'òpera es troben moltíssims llibrets, ja que el públic acostumava 
recordar, que l'òpera va tenir el seu origen en la poesia i el drama i no en la música i no va ser fins el segle XIX, en què els compositors van influir decisivament en la dramàtica de l'acció dominant la música sobre el text.

1.2.2 Literatura en la música: aquí es tracta de la denominada música programàtica, la qual té per objectiu evocar idees o imatges extramusicals en la ment de l'oient, representant musicalment una escena, imatge o estat d'ànim. Va ser corrent en el Romanticisme i en el segle XIX. Per avivar més aquesta associació es recorre sovint al títol d'una obra literària, per exemple la FaustSymphonie de F. Liszt o L'aprenent de bruixot de P. Dukas, ambdues amb textos de Goethe.

1.2.3 Música en la literatura: és l'únic dels tres mètodes que cau plenament dins l'àmbit de la literatura. El text adquireix una melodia pròpia mitjançant evocacions, incitaments o imitacions de la qualitat acústica de la veu (to, timbre, accent, estructura, entonació) o mitjançant imitació d'instruments musicals.

En aquest article s'estudiarà la funció de la música en el teatre guimeranià (àries, duets, cors, etc.), la seva influència en l'acció, l'impacte de la música vocal i el paper gairebé desconegut del dramaturg com a llibretista. Donada la gran extensió d'aquest tema, ens concentrarem només, però, en la música vocal.

\section{TEATRE MUSICAL ${ }^{4}$}

Guimerà va introduir molt aviat música en el seu teatre, al principi van ser només petites incidències amb algun instrument musical tocat dalt de l'escenari per algun actor. Poc després, però, la música instrumental i vocal van anar guanyant pes en les seves obres, les quals ofereixen alhora l'avantatge d'assolir la simultaneïtat de l'acció principal amb música fora d'escena (Becker 1976: 33) o de parlar amb acompanyament musical. Guimerà va mantenir sempre contactes molt estrets amb compositors de l'època proposant sovint ell mateix les obres, que creia més adients, encara que en una carta a Francesc Casanovas del 16-X-1894 va confessar: «Repeteixo que no hi entenc gens, trobant-me solament al alcanç de la música quan aquesta té sabor marcadament popular i en certes frases dramàtiques»; en la mateixa carta li suggereix musicar Rei i monjo,

a seguir la funció llegint-los alhora. Smith (1975: iii) compta que només a Itàlia en els segles XVII i XVIII van escriure-se'n més de 20.000.

${ }_{4}$ Existeixen pocs enregistraments de les obres musicals de Guimerà, per la qual cosa l'autora de l'article vol agrair al Sr. Jaume Tribó per haver posat a la seva disposició un DVD del recital, que va tenir lloc en el Liceu el 18 d'octubre de 2008 en ocasió de la representació de Tiefland amb cançons de Guimerà musicats per Morera, Vives i Pahissa a més de dos fragments de La catalane de Le Borne, l'ària «Psyche wandelt durch Säulenhallen» de Die toten Augen, les cançons «Ich war ein kleines Kind i «Ein Mädchen sass am Meeresstrand» de Liebesketten de d'Albert. 
L'ànima morta, El fill del rei, ${ }^{5}$ En Pòlvora i Judit de Welp (Guimerà 1978: 1476). Tanmateix en vida només va poder veure realitzat la darrera. Morera (1862-1942), Vives (1871-1932) i Pahissa (1880-1969), els més famosos compositors de la seva època, van musicar principalment les seves obres. L'evolució de les relacions de la música en l'obra guimeraniana es posa en evidència, si s'estudia en detall el paper de la música en nou peces musicals, les quals van des dels primers assaigs tímids de música incidental acabant amb òperes, a més de les musicalitzacions posteriors de drames ja representats. ${ }^{6}$ D'aquestes nou obres, les quals en realitat només en són set, ja que dues només són unes variants, quatre són òperes (Gal-la Placídia, La boja, Euda d'Uriac i Titaina), de les quals el mateix Guimerà va escriure el llibret, tres amb música incidental, ${ }^{7}$ on la música és només la «servidora» del text i en el fons es tracta senzillament d'obres del teatre parlat amb acompanyament musical (Jesús de Nazaret, Les monges de Sant Aimant i La resurrecció de Llàtzer) i dues operetes/sarsueles (La santa espina i La reina vella), les quals podrien classificar-se de «sarsuela catalana modernista» amb l'objectiu de presentar un espectacle total allunyat dels esquemes de la sarsuela castellana entrellaçant sovint el text amb música, cants i balls. A instàncies del mateix Guimerà es troba una forta presència de tonalitats orientals en moltes escenes musicals. Quant a la temàtica d'aquestes obres musicals, ja pel títol pot comprovar-se que van des d'un contingut històric romàgot $\mathrm{i}$ bíblicreligiós, passant per pseudollegendes medievals fins acabar amb una òpera amb una protagonista gitana.

\subsection{Gal·la Placídia (1879; estrenada com a òpera el 1913)}

Va ser la primera tragèdia de Guimerà, que va ser molt ben rebuda tant pel públic com per la crítica. En el seu pròleg l'autor esmenta com a models a Shakespeare, Schiller, Víctor Hugo i Ventura de la Vega alhora que comenta d'antuvi la impossibilitat de ser fidel als fets històrics perquè ni els historiadors han pogut esbrinar mai exactament qui va ser l'autor de l'assassinat d'Ataülf. A part d'aquest personatge, de la seva dona, Gal-la Placídia, i del got Sigeric, la resta són totes creacions del dramaturg. El 1913 el mateix autor va escriure el llibret servint de text de partida la tragèdia del mateix títol mitjançant escurçar escena per escena, ${ }^{8}$ la qual va estrenar-se en el Liceu al mateix any representant-s'hi

5 En El fill del rei ja hi va incorporada una llarga cançó recitada pel Bernadot: «És vella, vella, que esparvera» (Guimerà 1975: 217), la qual hauria pogut molt bé servir de base per a una ària.

${ }^{6}$ Més tard algunes altres obres van ser acompanyades de música, les quals, però, no van arribar a gaudir d'èxit i van continuar representar-se només com a teatre parlat, entre aquestes cal esmentar les operetes de Morera: La sala d'espera (1890) i La Baldirona (1892). Per la seva banda, Judith de Welp (1883) va conèixer una versió operística d'Antoni Lázaro i Perelló, sobre el qual l'autora d'aquest article malgrat intensives recerques només ha trobat una única referència en la biografia de Miracle (1958: 457). A instàncies de Lluís Via, Apel-les Mestres va musicar la «Cançó dels raiers» de Per dret diví després de la mort de Guimerà (Guimerà 1978: 759).

7 Segons les acotacions adesiara afloren en les obres guimeranianes mostres de música incidental suau, per exemple en El camí del sol o en Mossén Janot.

8 Normalment es compta que el text d'una òpera requereix tres vegades més de temps que el 
cinc vegades i reposant-s'hi el 1934. Pahissa hi posà la música, la qual va sorprendre als seus contemporanis per les seves audacies harmòniques. ${ }^{9}$ L'acció està situada a Barcelona i versa sobre els darrers dies del rei got. Com és corrent en musicalitzacions posteriors, els llibretistes aprofiten el «racconto a posteriori» de succesos tràgics per fer-ne «àries d'urlo» (Zierau 1994: 185), per exemple aquí trobem la de Sigeric: «Des de la infància mos pares he perdut» (Guimerà 1975: 29-30) o la de Vernulf: «Doncs bé, ja prou fingir» (Guimerà 1975: 35); molt colpidora és també l'ària de Vernulf sobre la seva lluita interna entre suïcidar-se amb el verí, que li va donar la seva mare, i el seu desig de viure: «Pom enciser» (Guimerà 1975: 108).

\subsection{Jesús de Nazaret (1894)}

És l'única obra de contingut clarament bíblico-religiós, la qual s'alinea amb la tradició del teatre religiós, que en aquella època, sobretot a França, estava de moda, influït per Ernest Renan (1823-1892) (Neumann 1999: 66-67). S'ha especulat sovint sobre la persona de Guimerà com a home religiós (Bacardit 2009: 184-188) i, tenint en compte l'època marcadament devota en què va viure i també les seves obres, la seva postura sembla més aviat que es decantava, tot i que moderada, cap a un concepte religiós popular, en el qual tant el paper de l'església com les forces sobrenaturals jugaven un gran paper. Un comentari seu certament irònic sobre Jesús de Nazaret, el trobem en una carta a Morera del 12- VIII-1907, en la qual li explica: «en quant a la figura de Jesús, no necessita cap preparació, perquè des de què venim al món se'ns en parla» (Guimerà 1978: 1511). En el seu teatre abunden manifestacions de religiositat popular, com per exemple misses, processons, benediccions, pregàries, etc. Guimerà era conscient de l'efecte que produien en el seu temps tals actes en el públic, ja que en una carta des de Madrid a la família Aldavert del 1898 comenta una representació de Mossén Janot: «Hi ha un moment en el tercer acte en què un home perdona a altre perquè entra a la casa la Mare de Déu del Roser, que va aixecar una tempestat llarguíssima d'aplausos (perdoneu-me l'elogi)» (Guimerà 1978: 1493). En Jesús de Nazaret, la lletra predomina clarament sobre la música, la funció de la qual és primàriament acompanyar els succesos. ${ }^{10}$ L'obra se solia representar per la Quaresma i la música venia distribuïda de la següent manera, segons ja d'antuvi Guimerà havia prescrit clarament: «Acte I. Preludi de l'acte ${ }^{11}$ i final del mateix. Acte II. Preludi de l'acte; preludi del quadre tercer, marxa de

d'una obra parlada, per la qual cosa un llibret s'haurà de reduir a una tercera part (Kaindl 1995: 61), ja que els diàlegs no tenen lloc entre els cantants, sinó entre aquests i la música (Link 1975: 136). Segons Istel (1914: 73), el text d'un llibret no serà mai prou curt.

9 Conferència del Sr. Tribó (v. nota 4).

10 En part recorda la musica fílmica de l'època del cinema mut, la qual era improvisada per un pianista present durant la sessió.

${ }_{11}$ Segons Saint- Saens, una òpera sense preludi és com un sopar sense sopa (citat a Raupp 1930: 255). 
l'enterrament de Llàtzer, i des de que Jesús es presenta en escena fins que cau el teló. Acte III. Preludi de l'acte; i en el quadre tercer des de que Jesús diu: «De genolls a mos peus; volteu la soca, etc», fins que s'acaba l'acte. Acte IV. Preludi de l'acte; final del quadre segon i preludi del tercer, i acabament de l'acte. Acte V. Preludi de l'acte; marxa del Calvari; preludi i marxa del temple, i des de que Caifàs diu: «Fills d'Israel, pregueu de genolls en terra», fins a la terminació de l'obra» (Guimerà 1975: 763-764). La música és completament instrumental a excepció dels dos versos finals, amb què es clou la peça, els quals són cantats per un cor interior d'àngels: «Glòria per sempre a Déu en les altures ! / Als homes de bon cor pau en la terra!» (Guimerà 1975: 910).

Les marxes constitueixen un signe musical, que denoten clarament l'estat d'ànim col-lectiu, en què es desenvolupa el succés; ja d'antuvi es pot reconèixer de què es tracta, ja sigui per indicar eufòria, alegria, triomf o enterrament. Per accentuar el dramatisme de l'acció, en Jesús de Nazaret tenen lloc tres marxes: la Marxa de l'enterrament de Llàtzer, ${ }^{12}$ la Marxa del Calvari i la Marxa del Temple. Les dues primeres, com el nom ja indica, acompanyen dos fets luctuosos, mentre la darrera serveix per recolzar l'entrada triomfal dels sacerdots en el temple.

\subsubsection{La resurrecció de Llàtzer (1907)}

Davant l'èxit de l'oratori La risurrezione di Lazaro (1898) de l'abat Lorenzo Perosi (1872-1956) ${ }^{13}$, que l'Associació Musical havia donat a conèixer a Barcelona, Guimerà devia inspirar-s'hi i prenent com a base Jesús de Nazaret, que amb cinc actes era molt extensa, va escurçar-la. D'aquí va aprofitar només tot el quadre segon de l'acte segon, el qual versa sobre l'enterrament i la ressurreció del Llàtzer conservant alhora la música i la Marxa de l'enterrament (Guimerà 1975: 817-30;1978: 1049-64). A més va subtitular-la «Visió» introduint-hi també un cor i una ària nova.

En una carta a Morera del 8-II-1907 l'anima a introduir-hi alguns cants: «No tingui por. Els dos quadres de la Resurrecció de Llàtzer aniran molt bé sols. Els personatges que hi surten (llevat de Jesús) són nous a l'obra [...] Què no li vindria de gust escriure alguna cosa per cant? Jo estic disposat a fer la lletra si ens posàvem d'acord. Al primer quadre podria haver-hi un cant de les vetlladores de Llàtzer; i en començar el segon, quan para la música, en Santpere, que té repartit el paper d'enterramorts, podria cantar el cant de la Mort» (Guimerà 1978: 1511-12). Ja d'antuvi Guimerà confrontava sovint el públic amb música o cançons, així, quan s'aixeca el teló, sona el cor de les ploraneres, les quals lamenten la mort del Llàtzer (Guimerà 1978: 1049-50). Més tard mentre el Jonàs prepara la sepultura en una roca, contribuirà a dramatitzar l'escena amb l'ària «Cant de la mort» (Guimerà 1978: 1055-56). De l'èxit d'aquesta

\footnotetext{
Segons Aviñoa (1985: 264), aquesta marxa va ser molt popular.

13 A més d'oratoris, Perosi va ser també autor de misses i concerts.
} 
versió abreujada, Guimerà esperava també: «Estic segur, que agradant molt aquests dos quadres, com agradaran, despertaran desigs de conèixer tota l'obra, i em sembla que l'any pròxim en Graner determinarà a posar tot el Jesús de Nazaret (Guimerà 1978: 1512).

\section{$2.3 \quad$ La boja (1894)}

A diferència de Gal-la Placídia, Guimerà va escriure primer el llibret, musicat per Morera, que no es va representar mai com a òpera. Es tracta d'una òpera verista,${ }^{14}$ les quals es caracteritzaven pel seu interès per a membres de classes socials baixes i normalment estaven situades en pobles i no en ciutats. En general, aquestes obres són bastant breus no passant dels dos actes. Com en totes les òperes veristes, el llibret té un gran predomini, la qual cosa demana molta més concentració en la lletra (Zierau 1994: 217). El motius principals veristes són, com en aquest cas, amor, gelosia i venjança (Zierau 1994: 55). La Joana, una perduda, que viu en una cova i treballa a una mina, s'enamora del Germà Albert i aquest d'ella, acabant tràgicament amb la mort d'ell. Quant a la música, es tracta d'una escriptura vocal molt avançada. ${ }^{15}$ La boja presenta una «ària d'urlo», molt bonica i colpidora, en la qual el Germà Albert narra la seva història tràgica (Guimerà 1978: 549-50) de com va matar la seva dona, que l'enganyava amb el seu propi germà. Guimerà comunica en una carta a Francesc Casanovas del 16-X-1894: «Concretant tenim que La boja està ja tota posada en música per En Morera; l'ha tocada al piano davant d'alguns amics i aquests diuen que és magnífica» (Guimerà 1978: 1476). Tanmateix el destí d'aquesta obra no va veure's coronat per l'èxit, ja que no va estrenar-se mai com a òpera, sí, però, revisada i ampliada com a teatre parlat el 1895 al Teatre Novetats. Sembla que més tard tampoc no va ser gaire ben representada, ja que en una carta a la família Aldavert des de Madrid del 8-III-1898 Guimerà es queixava: «Aquí no val posar les obres com me van posar La boja al Principal, que la van tenir de retirar tot seguit, i El fill del rei al Romea, que també feia fàstic (Guimerà 1978: 1491).

\subsection{Les monges de Sant Aimant (1895)}

El Novetats volia configurar amb tot luxe de detalls un tipus d'obra -lluny dels esquemes castellans- que s'aproximés als ideals teatrals en voga des de la renovació wagneriana; la partitura no havia d'ésser, doncs, l'única que calia tenir en compte, sinó que s'havien d'oferir espectacles «totals» complets i d'alt nivell artístic (Aviñoa 1985: 285). Ja el 1893 Morera cercava inspiració per fer un primer drama musical i per això va dirigir-se a Guimerà, el qual va escriure Les monges de Sant Aimant (Marfany 1974: 30). Per a l'escenografia van col-

14 Es podria considerar La traviata (1853) de Verdi i Carmen (1875) com a predecessores del Verisme, el qual, passant per la Cavalleria rusticana i Pagliacci, s'estén ben entrat el s. XX fins arribar a Eine florentinische Tragödie (1917) de Zemlinsky.

15 Conferència del Sr. Tribó (v. nota 4). 
laborar-hi els artistes més famosos de l'època: Soler i Rovirosa junt amb Moragas i Vilomara com a escenògrafs i Labarte com a figurista.

El drama duu el subtítol de «Llegenda dramàtica» en quatre actes i quinze quadres en vers. Com en les obres anteriors, es manifesta aquí també el predomini de la lletra sobre la música. Al llarg de tota l'obra es troben acotacions molt exactes i primmirades de quan i com ha d'intervenir la música: «Acte I. Preludi, seguint l'orquestra fins que Severí interromp el ball. - Tota l'escena de Pere l'Ermità. - En anar a acabar el quadre primer. - Mentre beuen a la taula, Roger, Tibalt i Renat. - I en acostar-se el final de l'acte. Acte II. Preludi, que acaba abans d'enraonar els actors. - Tot el dels bruixots i bruixes, afegint per a la melopea, quan diu Roger en l'escena III del primer quadre: «...Un tant sols! Un! Ma Euda!, i el següent: «Ah tu! O t'arrenco la llengua que no vol.» - Tot el quadre tercer i quart fins a caure el teló. Acte III. Preludi. - El monòleg de Roderic i en tant davallen la muntanya Roger i Euda. - El final del quadre primer. - El final del quadre segon i començament del tercer. Una part del quadre tercer fins a caure el teló. - Acte IV. Preludi. - Pas per l'escena de l'Emir i la seva comitiva. - Final del primer quadre i pas al segon. - Tot el quadre de l'assalt de les muralles. - Tot el quadre cinquè i apoteosi» (Guimerà 1978: 646).

Com ja en Jesús de Nazaret, la música aquí és incidental i serveix només d'acompanyament. En tota l'extensa peça només apareixen dues àries breus: la del creuat: «Ai adéu pares del cor / Ai adéu, / germanets i l'amor meu! / M'ha cridat Nostre Senyor / i me'n vaig, al pit la creu, / a la terra on prengui mort. / Si no torno no em ploreu!» (Guimerà 1978: 957) i la cantilena come-da-lontano molt melòdica del moazin, la qual hi confereix una nota de color local oriental: «Alà és Alà! No hi ha altre Alà que Alà. / Desperteu, i a pregar! / Alà és Alà! No hi ha altre Alà que Alà!» (Guimerà 1978: 980).

El final acaba amb una pregària general, la qual és una forma típica de les òperes veristes i tambe dels drames de Guimerà, és a dir el «moment religiós» (Zierau 1994: 168-72), en el qual s'aprofita per introduir cors i àries amb contingut religiós com a «preghiera» amb forta presència coral per denotar la participació activa del poble (Niemöller 1976: 342-44; Klotz 1980: 211).

El drama s'inicia amb un quadre, on tothom balla sense especificar què; després, però, el Severí els farà parar davant la vinguda imminent de l'Ermità i dels seus seguidors, que van pels pobles per a recrutar creuats per alliberar Jerusalem, i també perquè fa un mes que el senyor del castell s'ha mort. Durant tota l'escena primera fins que s'interromp el ball, l'orquestra continuarà sonant el preludi: «Severí: Ja prou de música (Pega garrotades als músics.) [...] / Bernat: Toqueu, toqueu. [...] / Severí: No ho vull. [...] / Bernat: Ja hem pagat els músics. [...] / Felipó: A ballar [...] / Severí: Amagueu les músiques [...] amagueu les músiques.» ${ }^{16}$ (Guimerà 1978: 848-54). Els músics, que toquen el ball, solen ser actors, que figuren sonar alguns instruments. Quan l'Ermità es fora, els pagesos volen continuar ballant, però ara seran interrom-

16 També en La festa del blat, l’oncle Telm farà parar la música: «Prou! Prou! Que m'eixordeu!» (Guimerà 1975: 1341). 
puts per una forta tempesta (Guimerà 1978: 861). Un altre ball, que té lloc dins l'obra, és quan la bruixa Urilda ${ }^{17}$ ordena les bruixes i bruixots de ballar entorn el cos del Roger: «Danseu que és núvia / que espera a son espós» referint-se a l'Euda que està a punt de fer els seus vots. Més tard, però, els manarà de parar: «Ja prou dansar» (Guimerà 1978: 904-05).

\subsubsection{Euda d'Uriac (1900)}

De tots els gèneres literaris, els drames són els més aptes per a servir de base per a un llibret; així Les monges de Sant Aimant van servir de text de partida per a Euda d'Uriac, ${ }^{18}$ la qual ja d'entrada ostenta un títol més suggestiu i amb més personalisme de la protagonista; el llibretista va ser el mateix Guimerà, ${ }^{19}$ si bé el compositor aquí va ser el mestre Vives. El text operístic segueix fidelment el text de partida, si bé notablement escurçat, com són els llibrets, que es basen en obres anteriors. Tanmateix Guimerà introdueix un canvi notori al final: mentre que en Les monges de Sant Aimant moren el dos amants, el Roger a conseqüència de les ferides rebudes en defensar Jerusalem i l'Euda de sentiment, en l'òpera, només mor el Roger de sentiment, quedant l'Euda afligida acompanyada de l'Ermità. Al mateix temps s'han eliminat totes les accions paral-leles secundàries, concentrant-se només en la trama principal. Mentre que en Les monges de Sant Aimant hi ha 28 personatges nominals, en Euda d'Uriach només n'hi ha 10. Com a novetat, en l'òpera s'hi ha introduït un paper de travesti en el pastor Roderic cantat per una soprano: «Ai! pobret del Moixaina! No gemeguis / que més pena en tinc jo, pobret Moixaina! / M'ha dit el rabadà que ell no volia / tocar-te a tu; que anava per la Xurris» (Guimerà s.d.: 24). ${ }^{20}$

La música de Vives és en part una glossa del Cant dels ocells ${ }^{21}$ per exemple la cançó del creuat, que també Morera va musicar, té la mateixa lletra que la del text de partida, però la melodia és ara la de la cançó popular. La primera vegada que l'Ermità apareix amb els seus monjos canta una cançó abrandada, la lletra de la qual recorda alguns motius de La marsellaise: «A les armes cristians, que l'hora arriba! / A les armes els pobres, els rics i els potentants» (Guimerà s.d.: 3). En aquesta cançó es pot comprovar l'impacte entre la mateixa lletra recitada

17 El nom d'Urilda pot tenir el seu origen en la vident Ulrica de Le bal masqué (1833) d'Auber amb llibret de E. Scribe i d'Un ballo in maschera (1859) de Verdi amb llibret d'A. Somma.

18 Guimerà va escriure també el poema Euda $i$ Roger, basat en el mateix tema (Guimerà 1978: 1428-29).

19 També V. Hugo, autor de Notre Dame de París, fou ell mateix el llibretista de l'òpera Esmeralda amb música de la compositora Louise Bertin.

${ }^{20}$ Aquesta escena recorda el quadre del pastor (també un paper de travesti) de Tannhäuser de l'escena tercera del primer acte, on a continuació passen els romeus cap a Roma, mentre que aquí poc després apareixeran l'Ermità i els seus monjos camí de la Terra Santa. En aquella època la influència de Wagner a Barcelona era molt forta, com ho demostra la fundació de l'Associació wagneriana el 1901 sota la presidència de J. Pena.

${ }^{21}$ Un dels arranjaments musicals més famosos és el de Pau Casals per a violoncello, amb el qual a partir del 1939 començava o acabava sempre els seus concerts arreu del món. 
només amb acompanyament musical com en el drama originari o com aquí cantada com a ària. ${ }^{22}$ En una òpera, les àries juguen un paper primordial no tan sols per motius lírics, sinó també per la seva funció de narrar retrospectivament fets passats, per exemple la mort del senyor del castell i de com aquest va desterrar el Roger, la història dels amors de l'Euda i el Roger, d'aquest amb la filla de l'Urilda o l'arenga de l'Ermità per animar la gent a seguir-lo per anar a alliberar Jerusalem. També tenen lloc alguns duets molt emotius, sobretot entre el Roger i l'Euda, l'Urilda i el Roger, l'Euda i Sor Mahalda i tres tercets: l'un entre Severí i dos vells, i dos altres entre el Roger, l'Euda i l'Ermità. El final acaba amb una pregària conjunta del poble: «Glòria a Déu en les altures / pels segles dels segles!!!...» (Guimerà, s.d.: 33), el qual recorda l'acabament de Jesús de Natzaret.

S'hi troba una forta presència dels cors ${ }^{23}$ el paper dels quals és important per demostrar la integració del sentiment comunitari (Zierau 1994: 185), i per tenir ocasió de prendre part en el transcurs de l'acció i alhora també d'influir-hi servint sovint d' «escenografia acústica». Aquests estan formats per diferents grups socials: monjos, poble, que encara té la dèria de ballar: «diu que plora Jesús i tothom plora / i també ens ha apenat. Fins la riera seguim-lo tots, / i quan s'allunyi, tornem aquí a ballar!» (Guimerà s.d.: 3), bruixes i bruixots, monges, quan l'Euda va a professar, mares, homes i al final una altra vegada el poble, el qual primer va contra l'Euda i el Roger pels seus amors «deshonests», però, amonestats per l'Ermità, es compadeixen més tard de la dissort d'ambdós amants i es posa al seu costat.

\subsection{La santa espina (1907)}

De tot el teatre guimeranià La santa espina, en tres actes i sis quadres, és la comedia fantàstica musical per excel-lència. El subtítol aclara de què es tracta d'una rondalla ${ }^{24}$ si bé en la partitura Morera ${ }^{25}$ va subtitular-la de sarsuela i, com Ramon Vinyes va definir molt bé, es tracta d'un «teatre musical parlat» (Gallén 1986: 447). Gual havia imposat unes característiques ben definides per a una

${ }^{22}$ Era també un temps de músiques nacionalistes, per exemple a França, La marsellaise, a Itàlia, moltes òperes de Verdi, sobretot els cors, i a Catalunya, Els segadors, La bandera i El cant de la senyera, les quals podien arribar a ser separatistes a causa del clima enfervorit provocat per les Bases de Manresa (Aviñoa 1993: 22;26), on el mateix Guimerà va pronunciar un discurs abrandat. El crit per a l'alliberacio de la Terra Santa podria interpretar-se també com un crit d'alliberació de Catalunya.

${ }^{23}$ Des de mitjans del segle XIX, amb la influència dels cors Clavé, hi havia a Catalunya una gran activitat coral, que culminà amb la fundació de l'Orfeó Català el 1891 i la Societat Coral de Catalunya Nova per Morera el 1896 a més de innombrables corals de barriades, parròquies i associacions.

${ }^{24}$ Segons J. Coromines (DECAT), «rondalla» és un mot peculiar del català antic d'origen incert. Té diferents accepcions, que van des de contes per a infants i joves fins a faula, història divertida poc seriosa o novel-leta.

25 Morera, esdevingut «Ministre de la Música», participà activament en les Festes Modernistes de Sitges (Cerdà 1997: 95). 
obra escènica: incorporació de la música, efectes escenogràfics sobtats, recreació d'un ambient llegendari o màgic i utilització alternada de prosa i vers (Fàbregas 1971: 115). Per altra banda, els Espectacles-Audicions Graner fent-se ressó també d'aquesta exigència demanaven espectacles totals, és a dir amb música, cançons, cors, balls i escenificacions plàstiques com la de Catalunya al final de La santa espina. A començaments del s. XX va desvetllar-se un gran interès per a rondalles populars $i$, sobretot en el Graner, era corrent glossar escènicament cançons i rondalles populars catalanes (El comte Arnau, La presó de Lleida, La dama d'Aragó), però, en contra de l'opinió de Fàbregas $(1971 ; 39)$ i de Gallén (1986: 442), La santa espina no és cap rondalla popular, sinó una creació literària de Guimerà, el qual segurament va subtitular-la «rondalla», tot volent incorporar-la a la moda del moment, mitificant alhora la llegenda i la història catalana. En una carta del 27-II-06, on demana la col-laboració musical de Vives, li comunica el que a primera vista sembla una contradicció i paradoxa: «L'obra serà una rondalla. [...] No tindrà caràcter còmic» (Guimerà 1978: 1508). Malgrat que fins llavors Guimerà havia treballat gairebé exclusivament amb Morera com a compositor, després d'Euda d'Uriach va preferir el prolífic Vives per a La santa espina, ja sigui perquè li devia agradar més la seva música, ja sigui perquè en aquell temps aquest era molt famós a Madrid i, entre moltes altres sarsueles, havia conegut un gran èxit amb Bohemios (1904), que el superà més tard amb Doña Francisquita (1923). En la mateixa carta li detalla exactament els indrets on hi ha d'haver música: «Jo no n'he parlat absolutament a cap músic, ni en Graner tampoc, fins saber la resposta vostra.» Més tard, però, quan li va dir que hi havia el costum de donar un tant per temporada i no per representacions, el compositor va tirarse enrera (Curet 1967: 421-422), per la qual cosa Guimerà va dirigir-se de nou al mestre Morera. ${ }^{26}$ Aquest va acceptar l'encàrrec i la seva composició amb molts números músicals i balls va resultar una de les seves obres més ben reeixides (Aviñoa 1986: 316) i sobretot la sardana va esdevenir una de les més populars i emblemàtiques de Catalunya. ${ }^{27}$ En una carta a Morera del novembre de 1906 Guimerà li indica exactament els llocs que han de ser musicats, demanant-li sobretot: «Si mentre parla de Montserrat, la música recordés vagament les coses de la terra nostra, ara els xiquets de Valls (no d'en Clavé: de Valls), la salve de Montserrat, ballorada del dia de festa major de les gralles de El Vendrell a Vilanova, a Sitges, potser també alguna cançó de Montserrat, algun ballet de la terra, com el del Ciri i altres coses de Catalunya que vós coneixeu més que jo» (Guimerà 1978: 1510-11). Tanmateix en una altra carta de Guimerà a Morera del 10-XI-1906, junt amb la qual li tramet ja el primer acte, es mostra més conciliant: «Allà a on em dieu que hi va bé música, és allà a on jo dic: "Està tot molt bé"» (Guimerà 1978: 1509). En una carta del 16-XI-1906 afalaga el compositor segurament per treure importància que abans s'hagués dirigit a Vives: «Cada dia estic més content de què sigueu vós qui posa la música a La santa espina» (Guimerà 1978: 1510). En una altra

\footnotetext{
${ }^{26}$ Morera més tard s'exclamava que cobrava pocs drets d'autor malgrat que la sardana es tocava pertot arreu (Aviñoa 1993: 7;46).

${ }^{27}$ La música d'aquesta sardana va sonar durant l'enterrament de Guimerà (Miracle 1958: 447).
} 
carta del mateix novembre, les úniques correccions que hi posa sónः «Per fer sentir al públic l'amor a la nostra terra, guiant-lo al que ha de venir, convé, mentre parla el cabdill corsari, que la música sigui lleugeríssima com venint de llarga distància, fent onades tranquil-les d'aigua o de vent lleuger» (Guimerà 1978: 1511).

En la rondalla hi ha només tres solistes: el Gueridò, el joglar Ulric i la sirena Rosa Vera. Cada u d'aquests solistes cantarà una cançó, llevat el joglar que en cantarà dues: la cançó del Gueridò de caire popular serà: «Ja la magrana al magraner» (Guimerà 1978: 1000) a l'inici abans d'aixecar-se el teló, la qual repetirà un cop rei per indicar que s'enyora dels seus temps de vaquer i també la música recordarà els aires de la vacada de l'acte primer (Guimerà 1978: 1038); el joglar Ulric, ja abans d'alçar-se el teló de l'acte segon, cantarà la cançó molt coneguda, però en certa manera macabra, ja que en la calavera d'un cavaller mort, anys més tard hi niuran una parella d'ocells: «És la cançó més sentida / la cançó que surt del cor: / Amor, que l'amor és vida! / Amor, que visca l'amor!» (Guimerà 1978: 1013) i, poc després, el mateix joglar acompanyarà un «ball d'espases» grotesc dels cavallers amb la següent corranda: «D'un raig de sol l'han feta / l'espasa de l'honor; / i els diables l'han batuda / l'espasa del traïdor» (Guimerà 1978: 1016-17). La Rosa Vera, per la seva banda, cantarà una cançó encomiàstica a l'Amor, la qual des del mar come-da-lontano, se sentirà ja abans de què apareixi en escena: «Ai mar que m'acarones, / ai mar, ai mar, on só...?» (Guimerà 1978: 1020-22) i, quan deixa de cantar, segons les acotacions de Guimerà se sentirà la remor de la mar, feta d'harmonia musical; més tard la sirena proseguirà amb la mateixa cançó de més amunt: «O mar que ets endolcida» (Guimerà 1978: 1022). Segons les acotacions, «quan deixa de cantar, s'ha d'anar sentint, feta d'harmonia musical, la remor de la mar tot el restant d'aquest quadre, lligant-se dita harmonia sense interrupció amb el començament de l'altre quadre» (Guimerà 1978: 1020). També el cant de les bruixes i bruixots, mentre esperen la Sabata del Gegant dels Castellots de Bromes, anirà acompanyat d'una lleugera harmonia, que anirà creixent i destacant-se fins que caurà el teló (Guimerà 1978: 1011).

Més importància tenen els cors, la presència dels quals es troben al llarg de tota la peça, els quals van també sovint acompanyats de balls. Aquests cors estan formats per diferents grups: treballadors de la masia de cal Magraner (trepitjadors, ${ }^{28}$ veremadors i veremadores, traginers, fadrins), bruixes i bruixots, abracandaris, dones de Moreria, noies catalanes captives i cortesans. L'obra es clourà amb un cant a l'amor, que ressonarà pertot arreu: «Amor, amor, la gran victòria humana! / Que sia beneit el teu sant nom! / T'adorem en el sol que ens agermana, / que el sol surt per tothom» (Guimerà 1978: 1048). En la «Cançó de Moreria», el compositor introdueix tonalitats orientals (Guimerà 1978: 1040) per donar entrada aviat a un dels cants més emblemàtics del repertori català i de

28 Potser com a al-lusió al text de Els segadors, en La santa espina trobem com a contrapartida la «Cançó dels veremadors», on el text presenta clares connotacions de crida a la lluita armada amb eines de treball: «És nostra arma el veremall, / i com els tirans fem guerra: / els tirans sedegen sang; / nosaltres sang de la terra» (Guimerà 1978: 1002). 
les sardanes: «Som i serem gent catalana / tant si es vol com si no es vol» (Guimerà 1978: 1042), la qual primer havia estat composta per a dos sopranos i més tard va transcriure's per a cobla i gran cor, a continuació les donzelles catalanes ballaran caminant la sardana amb crits d'alegria (Guimerà 1978: 1048).

La importància de les marxes per acompanyar un succés triomfal es troba confirmada en tres ocasions: a) quan els abracandaris van a buscar el príncep Arnolt per nomenar-lo rei, (Guimerà 1978: 1035), b) quan, ja rei, es presenta davant els seus cortesans, s'indica que l'acompanyarà una lleugera marxa sense precisar quina (Guimerà 1978: 1036), la qual creix amb gran espetec quan ve la comitiva, i c) una marxa nupcial ${ }^{29}$ amb text després de les noces de l'Arnolt (Gueridó) amb la Maria (Guimerà 1978: 1045-46), la qual vol ser potser una reminiscència de la de Mendelssohn-Bartholdy, que va escriure per a Somni de nit d'estiu de Shakespeare. ${ }^{30}$

\subsection{La reina vella $(\mathbf{1 9 0 8 )}$}

Guimerà no era cap monàrquic declarat, però sí, reverent davant la monarquia, tot i que creia que els pobles tenen dret a expressar-se col-lectivament (Fàbregas 1971: 189). Va escriure dues obres, on en el títol figura el lexema «reina», l'una, La reina vella, sense contingut polític, i l'altra, La reina jova, amb un missatge revolucionari, així per esmentar només un exemple musical no s'hi tocarà cap marxa reial, sinó la «Marxa de la Nació» (Guimerà 1975: 446).

La reina vella presenta en tres quadres els darrers dies d'una reina octogenària,$^{31}$ la qual torna al poble de muntanya, on havia passat la seva infantesa i on mor. En aixecar-se el teló, el públic és confrontat amb dues dames de la cort, les quals canten un duet a mitja veu per no despertar la reina (Guimerà 1978: 1065-66). A més d'aquest duet, els cavallers de la cort cantaran cants encomiàstics per a la reina: «Oh Reina de les Reines, soberana, / tot virtut i saber!...» (Guimerà 1978: 1069-70;1072-74).

En una carta a Morera del 26-IV-1907, Guimerà li aconsella com ha de posar la música «cantant en Serní el mateix en música (si li sembla) que ha de cantar en arribar al segon quadre, però amb altra lletra: Aixís com allí diu: «Ja demanen al portal / la flor de la satalia», ara dirà que la flor de la satalia ha tornat, etc (....) el pagès pot ser en Puiggener (si li va bé) i tot caminant pot cantar una cosa llarga, trista, resignada, un xic que faci cant àrab si és que vosté troba que hi diu» (Guimerà 1978: 1512-13). Efectivament, el Serní, un vellet cec octogenari, que havia estat enamorat de la reina en la seva joventut, encara se'n

29 A La Miralta, després de la cerimònia nupcial del Carles i la Dèvora, donya Nadala esmenta que es tocarà la «Marxa de les torxes» del temps dels romans. En realitat es tracta de la «Dansa de les torxes» semblant a la polonesa procedent de Grècia i Roma. Cap l'any 300 l'emperador Constantí va fer incloure-la en el protocol de la cort. I àdhuc el 1913 va ballar-se encara en la cort imperial prussiana en ocasió de les noces de la filla de l'emperador.

30 Veg. Soler (2012).

31 Maria Guerrero, que va representar la protagonista, tenia en aquella època 40 anys. 
recorda d'ella i apareix per primera vegada cantant fora d'escena: «Ja demanen al portal / la flor de la satalia» (Guimerà 1978: 1075) i, un cop s'ha assabentat que la reina és al poble, tornarà a cantar, però amb el text canviat al-ludint ara al nom d'aquella (Blanca): «Ja ha tornat la Blancaflor / la flor de la satalia (Guimerà 1978: 1081).

Com succeeix sovint en el teatre guimeranià, el quadre segon acaba amb una música que es lliga amb la pregària del tercer acte. A diferència de les pregàries en forma d'ària, les quals ja es troben sovint en òperes anteriors, aquesta forma de pregària coral és una forma típica de les òperes veristes (Niemöller 1976: 345) i també dels drames de Guimerà, en la qual la veu del poble unida forma un transfons religiós. Segons les acotacions de l'autor, «la música alegre amb què finalitza el quadre anterior es transforma a l'aparèixer aquest en harmonia de pregària. No hi haurà ningú a l'escena. Les veus de la pregària seran cap a la banda dreta, ben lluny, i sense acostar-se» (Guimerà 1978: 1078).

En l'obra es troben dos solistes: Serní i Quirze tenint un gran protagonisme els cors, els quals alternen sovint amb un solista. En començar la sembra, el poble cantarà en to de pregària: «En nom de Déu comença la sembrada», a la qual cosa el Quirze contestarà bo i sembrant: «Ai caminet de la vida», cantant en diàleg amb el poble l'inici de la «Cançó de les Arades», el missatge primordial de la qual gira entorn a la sembra: «el gra li deia a la terra; / besa'm que jo et besaré» (Guimerà 1978: 1083-84). A continuació el Quirze marxa cantant fora d'escena per figurar que el camp és molt llarg. Ja abans de començar la sembra, la gent jova canta i balla la festa de les Arades i el poble es parteix en dues colles, per entremig de les quals passa la reina i el Serní (Guimerà 1978: 1078). També hi trobem la «Cançó del Ram», una cançó coral pseudopopular, la qual les noies del poble mig ballen mentre fan un ram: «Posa-li bojacs, / unes perpetuïnes» (Guimerà 1978: 1080). En resum, l'obra és un cant a la naturalesa silvestre (satalia, ram) i a la naturalesa cultivada (sembra), temes típics de l'ideari modernista.

El final acaba amb una pregària per la reina morta acompanyada dels gemecs del Serní i l'espinguet dels clarins que es van allunyant. En una carta del 26-IV-1907 a Morera, Guimerà mostra de nou el seu interès per introduir efectes musicals: «Li deia en el segon acte que els clarins fossin a l'escenari perquè al final de l'obra faria molt efecte, mentre la cort s'endugués ràpidament, feréstegament, a la Reina en la llitera... i altres tocs de clarins o trompetes o no sé que són, a estil d'aquells tocs de cavalleria que són tan esgarrifosos» (Guimerà 1978: 1513).

\subsection{Titaina (publicada el 1910; estrenada en el Liceu el 1916)}

La literatura del segle XIX va interessar-se sovint envers personatges del medi gitano (Carmen, Esmeralda, Preziosa) contemplant-los des de dos diferents punts de vista completament contraris: per una part, com a persones perilloses i asocials, i per l'altra, amb motiu de la influència romàntica, com a persones amants de la llibertat. Sobretot les gitanes eren considerades com a dones exòtiques i amants boniques, les quals mostraven un especial interès per joies 
barates. En resum, es podria dir que, en el fons, el ball, la música i els lladrocinis eren llurs característiques (Angermüller 1976: 132-134). Titaina gira entorn a dos gitanos, Titaina i Nyerris, en els quals apareixen els clixés esterotípics d'aquesta raça: la dona es dedica a cantar, ballar i vendre quincalla i l'home a robar i a estafar, el qual amb la seva ària cínica defineix molt encertadament el prototipus del lladre: «Tot el món fora meu / si no em vegessin quan ho prendria. / Tu que t'alabes de lo que és teu, / t'ho deixà un lladre un dia» (Guimerà 1975: 1103). Per la seva banda, la Titania, practica les arts endivinatòries i, quan troba per primera vegada l'Eudald, que l'ha defensada de les befes del poble, li pronosticarà: «Quan sentis en el cor / trucar la veu de l'amor / obre els llavis i beu la llum del dia» (Guimerà 1975: 1100).

Titaina va ser una obra d'encàrrec en vers i tres actes, la qual va representar-se sis vegades; també va conèixer una versió italiana de Francesc Casanovas. Quant al llibret, l'argument de Titaina podria considerar-se com el d'una òpera verista. ${ }^{32}$ Els duets o tercets són construits a manera de diàleg, per la qual cosa tenen lloc poques àries; les dues àries més importants són la del Nyerris, que hem vist més amunt, i la de la Titaina. La d'aquesta darrera és un cant dins del cant, és a dir que, per accentuar el medi social es recorre a cançons populars o pseudopopulars i per destacar dins una òpera que algú canta, s'utilitza l'estratagema de què un personatge demani a algú altre que canti o comentarà que algú canta, per exemple l'Anton dirà: «Qui és que canta? Qui canta?» a fi d'introduir la cançó de la Titaina: «Venc anells i tumbagues - que donen sort» (Guimerà 1978: 1093-95). Cal destacar també alguns duets, per exemple els de l'hostalera i l'Eudald (Guimerà 1978: 1090-92), el del Nyerris i la Titaina (Guimerà 1978: 1106-09), el de l'Antoni i l'Eudald (Guimerà 1978: 1109-10), el de la Titaina i l'Eudald (Guimerà 1978: 1100-14) i el tercet final de la Titaina, l'Eudald i el Nyerris (Guimerà 1978: 114-17). La presència dels cors és molt notòria, per exemple el cor de les mosses de l'hostal, amb què comença l'obra: «Gran mercat comença; / el millor de l'any. / Pararem les taules, / que vindran amb fam», seguint a continuació els cants alternants entre elles i l'hostalera, que les renya perquè canten i no fan res: «Què feu aquí totes, / mosses de l'hostal? / Mireu que a la cuina / hi ha molt que cuinar» (Guimerà 1978: 1087-89). Altres cors seran els de les pageses i pagesos, a vegades a l'uníson, a vegades per separat (Guimerà 1978: 1092-93), per la seva banda, l'Anton i el Tomàs i també l'Eudald alternaran amb solos amb el cor dels pagesos (Guimerà 1978: 1099;1106) i també amb la Titaina, quan li demanen que canti i balli (Guimerà 1978: 1095-96) per més tard mirar d'emborratxar-la (Guimerà 1978: 1096-1101). El cataclisme final ve sovint retardat per moments reposats (Zierau 1994: 52), els quals no han de veure res amb la trama, per exemple jugar a cartes, cançó i ball de la Titaina, i igual que a Tiefland (Terra baixa), Liebesketten (Cadenes d'amor) ${ }^{33}$ o Cavalleria rusticana, tampoc no faltarà l'«ària d'urlo»: «Vaig nèixer no sé on; / la mare

32 Fàbregas (1971: 40; 114-118) considera Titània com a obra modernista supeditada a l'Obra d'Art, tot i que al meu parer tant la protagonista com les seves àries no presenten cap connexió amb «l'Art», sinó més aviat amb el folklore típic de l'ambient gitano i el desenvolupament de l'acció permet més aviat de classificar-la com a obra verista.

33 Tiefland i Liebesketten les estudiarem amb més detall més avall. 
deixà el món / quan jo era bonica, / i el pare em va emportar / tot temps d'ací d'allà» (Guimerà 1978: 1112). Típic també de les òperes veristes és que la mort no es presentada ni verbal ni musical (Zierau 1994: 52), per la qual cosa tampoc no hi ha cap ària dels moribunds a l'estil dels finals de Verdi o Puccini.

Si comparem el final de Titaina amb els d'algunes òperes veristes, per exemple Cavalleria rusticana (1890), Pagliacci (1892), Tiefland (1903) i Liebesketten (1912) es veu tot seguit que totes segueixen més o menys el mateix esquema: al final es troben cara a cara els dos contrincants més la dona estimada, normalment l'arma homicida és el ganivet, que és l'arma dels pobres, o, com en el cas de Terra baixa/Tiefland, les meres mans; la lluita serà breu, però donarà encara ocasió de què es produeixi un breu intercanvi de mots, bo i acabant amb una frase curta molt característica. El cor, si hi és present, contemplarà estupefacte el drama per després lamentar la tragèdia, que acaben de presenciar. Només Terra baixa/Tiefland i Titania acabaran amb un lieto fine, és a dir que morirà l'amant que feia nosa:

a) Tiefland amb música d'E. d'Albert: al final es troben aplegats: Manelic/ Pedro (tenor) - Marta (soprano) - Sebastià/Sebastiano (baríton) ${ }^{34}$. Els dos homes combaten a mort davant la Marta, la qual cosa recorda la lluita que el Manelic va tenir amb el llop. En morir el Sebastiano escanyat, el Pedro/Manelic proferirà el famós crit: «Ich habe den Wolf erwürgt!» («He mort el llop!») i a continuació tornarà a la terra alta amb la Marta acompanyats d'una música triomfal.

b) Liebesketten, basada en La filla del mar també de d'Albert: Pere Màrtir/Peter Martin (tenor) - Sadika/Àgata (soprano) - Noel (baix). A diferència de La filla del mar, on el final l'Àgata mata el Pere Màrtir amb una fitora i després ella se suïcida, en la versió operística, el Noel tirarà un rampogoll al Peter Martin, però la Sadika serà més ràpida i s'interposarà morint ella en el seu lloc. El final acaba amb un res del cor de pescadors i amb una breu ària del Peter Martin, que anuncia la seva decisió d'anar a pescar al perillós mar del Nord, d'on probablement no en tornarà.

c) Titaina: Eudald (tenor) - Titaina (soprano) - Nyerris (baríton). Mentre els dos homes lluiten, Titaina agafa un ganivet de la cuina i el clava a l'esquena del Nyerris. Aquest final, que comença en un tercet, acabarà en un duet d'ambdós amants, els quals celebren el lieto fine: «Eudald: Queda't aquí a fer niu. / Titaina: Per sempre? / Eudald: Per sempre» (Guimerà 1978: 1115-17).

d) Cavalleria rusticana (1890) de P. Mascagni: Turiddu (tenor) - Alfio (baríton). La lluita amb un ganivet té lloc fora d'escena i acaba amb el famós crit d'una dona: «Turiddu é morto!», trobant-se en l'escenari només la mare de Turiddu i la seva promesa, Santuzza.

e) Pagliacci (1892) de R. Leoncavallo: Canio (tenor) - Nedda (soprano) - Silvio (baríton). El Canio mata amb un punyal la Nedda en l'escenari davant de tot el públic, el qual pren part amb comentaris adients sobre el desenllaç

${ }^{34}$ Normalment en les òperes el tenor sol representar el personatge bo mentre que el baríton o el baix seran els malvats. 
fatal, i el Silvio, en voler salvar-la, és també assassinat. Dirigint-se al públic, el Canio pronunciarà breument $\mathrm{i}$ dramàticament sense cantar la coneguda frase: «La commedia è finita!».

\section{MUSICALITZACIONS POSTERIORS}

\subsection{Catalunya}

A més de les obres musicals tractades més amunt, cal esmentar els intents no reeixits tant d'Albéniz com de Morera de musicar Mar i cel (1888). Ambdós compositors tenien els drets, però, amb gran pesar de Guimerà, no van arribar a acabar-la mai. ${ }^{35}$ No va ser fins al 1988, cent anys més tard de la seva estrena, que Dagoll Dagom $^{36}$ i Xavier Bru de Sala (1952-) van fer-ne un musical a l'estil nord-americà amb música de A. Guinovart (1962-), el qual va reposar-se el 2005-06, ${ }^{37}$ però a diferència d'aquells aquí gairebé només es canta i a penes es parla. El llibret ha sofert alguns canvis essencials a fi d'adaptar-se més al gust i a les expectacions del públic de mires més cosmopolites de finals del segle XX: s'hi ha introduït un pròleg, un interludi, que escenifica un somni de la Blanca en un zoco moro, i un epíleg; en la tragèdia el pare fereix la Blanca per comptes del Saïd i aquest la pren llençant-se junts al mar, deixant el final obert; en el musical, el pare matarà d'un tret l'arraix i la Blanca se suïcidarà, abans, però, els amants tenen ocasió de cantar un duet creuat, que fa referència al títol de l'obra: «Sóc el mar, / ets el mar. / Ets el cel... / sóc el cel... / que es troben en un punt de l'infinit.» La Blanca és l'única protagonista femenina de Guimerà; en el musical, pel contrari ja no és novícia, sinó promesa del capità cristià, i té companyes de viatge, l'acció és més brutal i el final més tràgic, si bé es clou amb l'apoteòsic cant esperançador de l'Himne dels pirates, ${ }^{38}$ la melodia més emblemàtica de l'obra, la qual es canta dues vegades: al principi, els pirates voldran anorrear tot el món, definint-se ells mateixos així com el vaixell com «un cavall desbocat per les ones», el qual passarà a ser al final «un cavall amansit per les ones». ${ }^{39}$

35 Es conserva un esborrany de la partitura de Morera del 1911-1914. Per altra banda, el 1897 La Veu de Sitges anunciava: «Això sense comptar amb Mar i cel que ja té llest l'Isaac Albéniz que no tardarem gaire a veure entre nosaltres» (Aviñoa 1985: 282).

36 El nom de Dagoll Dagom procedeix d'un sobrenom amistós de Joan Ollé, el primer director de la companyia. En l'actualitat n'és Joan Lluís Bozzo (1953-).

37 El 2006 va estrenar-se a Madrid amb el títol Mar y cielo. El director alemany Harmut H. Forche va veure Mar i cel a Barcelona i li va agradar tant que el va traduir a l'alemany amb el títol Der Himmel und das Meer, el qual va representar-se en les temporades del 2006-07 i del 2007-08 en l'Opernhaus de Halle. El públic va acollir-la favorablement, al contrari de la crítica, la qual, en general, va pronunciar-se negativament.

${ }^{38}$ La melodia de la tornada presenta clares influències del leit motiv del musical de Les girls (1957) amb música de Cole Porter i guió de John Patrick, el qual fou filmat per George Cukor.

39 El paper del vaixell, el qual oscil-la i es mou segons les necessitats de l'acció, té una gran importància en el musical ja que tota l'obra es desenvolupa a coberta, a diferència de la tragèdia que té lloc només en un camarot dels baixos. 


\subsection{Estranger}

En vida del dramaturg van estrenar-se a l'estranger quatre òperes (Tiefland, La catalane, Liebesketten i La nereide) de la ploma de quatre llibretistes (Rudolf Lothar, ${ }^{40}$ Louis Tiercelin+ Paul Ferrier ${ }^{41}$ i Ferdinando Fontana ${ }^{42}$ ) i tres compositors (Eugen d'Albert, ${ }^{43}$ Fernand Le Borne ${ }^{44}$ i Ulisse Trovati ${ }^{45}$ ). Totes les musicalitzacions es basen en llibrets, que foren escrits pel públic del país receptor, la qual cosa garanteix d'antuvi una acceptació més segura ja que s'adrecen i s'adapten a la seva cultura. Segons Miracle (1958: 439), Fontana havia demanat autorització a Guimerà per escriure un llibret en italià de Terra baixa i havia pensat en primer lloc en Puccini per musicar-lo, si bé el dramaturg català va negar-s'hi perquè ja havia concedit els drets a d'Albert i Le Borne. Més tard va cedir-li la traducció de La filla del mar ara bé només per l'italià, atès que d'Albert ja tenia els drets per a l'alemany.

\subsubsection{Terra baixa (estrenada el 1896 en cast.; el 1897 en cat.)}

\subsubsection{Tiefland (1903)}

El camí, que va dur a la gènesi de Tiefland, és bastant alambinat i degut a molts atzars: una comtessa hongaresa va veure la representació de Terra baixa a Itàlia, on va representar-se sense que Guimerà ho sabés. Va agradar-li tant que el 1900 va encarregar a l'agent teatral Minkus de fer-la traduir a l'alemany perquè ella mateixa volia representar la Marta. Minkus va contactar el llibretista Lothar, però, quan aquest va tenir-la llesta, la comtessa s'havia casat i havia oblidat la seva dèria de dedicar-se al teatre. Contra la voluntat de Lothar, Minkus va enviar el manuscrit als grans teatres alemanys i la casualitat va voler

40 Pseudònim de Rudolph Spitze (1865-1943), el qual fou un llibretista molt famòs en la seva època; la seva obra es pot dividir en dos grups: l'un, influït pel Verisme i l'altre, per l'òpera lírica.

${ }^{41}$ Tiercelin (1849-1915) era un dramaturg i poeta i Ferrier (1843-1920) havia exercit d'advocat a Montpeller, abans d'anar-se'n a París per dedicar-se a escriure comèdies i llibrets. En aquella època a França era corrent que dos llibretistes escrivissin el llibret (Gier 1988: 36).

${ }^{42}$ Fontana (1850-1919) era un periodista, comediògraf, traductor i llibretista molt prolífic, el qual va formar part de la segona Scapigliatura. Fou el traductor a l'italià de Tiefland (Terra bassa), la qual va estrenar-se en el Liceu el 1910.

${ }^{43}$ Després de la mort de R. Wagner, l'òpera alemanya estava estancada. Als voltants del 1890 apareix una nova generació de compositors, entre d'altres d'Albert d'origen anglès (1864-1932), el qual amb Tiefland va musicar l'òpera més important del Verisme alemany. Va ser deixeble de F. Liszt i va deixar una gran obra amb vint-i-una òperes, a més de concerts, sonates, lieder i simfonies.

${ }^{44}$ El compositor belga Le Borne (1862-1929) havia estat alumne de Gounod, Massenet, Saint-Saëns i Franck. La catalane era la primera òpera, que estrenava a París. En total va compondre onze òperes, a més de dos ballets, concerts per orquestra i música de càmara, dues misses solemnes, cantates i motets.

${ }^{45}$ Després dels seus estudis, Trovati (1868-1940) va ser nomenat el 1896 mestre de la capella de S. Ambrogio, que va dirigir durant 25 anys, i professor d'harmonia i contrapunt del Liceo musicale Paganini de Gènova. 
que el director musical de l'Òpera Reial de Dresden, Ernst von Schuch, mentre esperava ser rebut, fullegés un munt de manuscrits rebutjats, entre els quals hi havia Terra baixa. En llegir-lo, va entusiasmar-s'hi tot seguit i va contactar d'Albert per musicar-la. Terra baixa té tres actes: el primer, amb dotze escenes, el segon, amb deu i el tercer, amb onze. Tiefland consta d'una obertura i dos actes; el primer acte té onze escenes i el segon, deu, la qual cosa ja assenyala formalment una acció molt més compacta; el final de Tiefland ja s'ha tractat més amunt. L'estrena de Tiefland va tenir lloc a Praga el 15 de novembre de 1903, on fou molt ben rebuda, mentre que a Alemanya primer va resultar un fracàs, però, per consell del seu editor van refer-la i sobretot escurçar-la, tenint després un gran èxit, ${ }^{46}$ el qual ha perdurat fins en l'actualitat. Malgrat que a Guimerà no li agradava que li rectifiquessin els textos (Guimerà 1978: $1485 ; 1487 ; 1489)$ i, en contra del que Lothar temia, el dramaturg català era un gran admirador seu i estava molt satisfet del llibret de Tiefland (Raupp 1930: 180), tot i que en una carta a d'Albert, el 1908, va confessar que no trobava cap semblança amb el text original (Raupp 1930: 222).

\subsubsection{Terra bassa (1910)}

El 1910 Tiefland va representar-se al Liceu en versió italiana amb la presència de Guimerà, la qual no va tenir gaire èxit. En el mateix any J. Pena va adaptar el llibret alemany al català si bé orientant-se més cap al text guimeranià $\mathrm{i}$ introduint-hi dues sardanes: L'ametller d'A. Botey i A Pau Casals de J. Garreta (Neumann 1999: 138). Aquesta versió, que tampoc va tenir gaire èxit, no va ser estrenada fins el 1924 en el Novetats.

\subsubsection{Tiefland (film, 1933-1954) $)^{47}$}

Tiefland s'alinea en la tradició de les pel-lícoles alemanyes de muntanya, l'iniciador de les quals va ser Arnold Fanck. La directora i protagonista principal (Marta) va ser Leni Riefenstahl, la qual va donar més protagonisme a la promesa del Sebastiano, la qual s'adeia més a la seva pròpia personalitat que la de la submisa Marta. A part d'alguns canvis personals i temàtics, segueix bastant fidelment l'òpera alemanya, si bé ha traslladat l'acció en l'època de Goya a més d'introduir-hi molt color local espanyol. Karajan havia de dirigir la música fílmica, pero el seu cachet era massa onerós, per la que cosa ho van encarregar a Herbert Windt, el qual ja havia compost la música per al film Olympia, sobre

46 En la temporada del 1907/08 va representar-se més de 100 vegades a la Komische Oper de Berlín i 463 en tot Alemanya; en la temporada del 1908/09 van ser un total de 647.

${ }^{47}$ La llarga gènesi del rodatge va ser per motius bèl-lics. En temps del cinema mut va ser filmada a més a Catalunya, als Estats Units i a Itàlia. En temps del sonor, cal esmentar Tierra baja (Mèxic 1950) amb Pedro Armendáriz com a Manelic. 
els Jocs Olímpics de Berlín del 1936, també amb Riefenstahl como a directora. Quan l'acció té lloc en l'alta muntanya o en la vall amb els protagonistes principals sona la música operística, però amb la gent del poble, en el castell o amb els cavalls i toros es recorre a música típica popular espanyola.

\subsubsection{La catalane $(1907)^{48}$}

Encara que va estrenar-se posteriorment que Tiefland, el 1898 Le Borne ja havia demanat a Guimerà el permís per musicar Terra baixa, que havia vist a París. Guimerà va concedir-l'hi amb aquesta frase: «no tinc lo pensament de deixar posar en música a ningú més que a vós aquesta obra.» En la mateixa carta li recalcava més avall: «Coneixeu música popular de Catalunya? Ja sabreu que en aquesta part d'Espanya, la música andalusa és tan forastera com a França. Per si no la coneixeu i us pot servir, us envio alguna de la moltíssima música popular que aquí tenim recollida i que es canta encara en nostres muntanyes» (Guimerà 1978: 1494). Efectivament en el llibret s'esmenta explícitament que es balla una sardana en una rotllana ${ }^{49}$ (Férrier+Tiercelin 1907: 57;60), si bé segons d'Ors (1950: 488), que havia assistit a l'estrena a París, va ballar-s'hi «un fandango». D'altra banda, alguns crítics van opinar que les danses no eren «gaire espanyoles» (Pierre Lalo, Temps, Feuilleton La Musique, 29 maig 1907).

Lothar i Albert havien demanat el 1900 permís a Guimerà, el qual va concedir-los-hi sense dir res dels drets a Le Borne dos anys abans, el qual fins ara no l'havia representada. El fet d'haver atorgat gairebé simultàniament a dos compositors els drets de musicar una mateixa obra va reportar més tard disgustos a Guimerà i a d'Albert. Tiefland va representar-se a París el maig de 1907, on Le Borne va veure-la. Davant el gran èxit de Tiefland en comparació amb el fracàs de La catalane, Le Borne va dur a Guimerà als tribunals al-legant que només ell tenia els drets en exclusiva. El compositor francès va guanyar i d'Albert i Guimerà van haver de cedir-li part de llurs beneficis.

Terra baixa és un drama en prosa mentre que La catalane és un drama líric en vers i quatre actes, un dels quals és un pròleg. L'argument segueix bastant fidelment l'original català. Com a leitmotiv trobem el cor dels pagesos, el qual entona un cant de lloança als catalans: «Citadin et citadine, / Citadin et paysan, / Plus belle est la Catalane, / Plus brave est le Catalan». D'Ors (1950: 489) va anomenar-la «La favorita rusticana», ja que considerava que Le Borne havia volgut fer una rèplica de la Cavalleria rusticana de Mascagni junt amb el tema de La favorita, tot i que no va acabar de reeixir-hi del tot.

48 A diferència de Tiefland, de la qual existeixen diversos enregistrements musicals, no se'n disposa de cap de La catalane.

49 En una carta a Vinardell del 21-XII-1903, Guimerà comenta que «En Le Borne em va dir que la sardana que havia posat en l'Òpera era autèntica i popular a Catalunya i que li havia procurada un músic català; i com me va afegir que ja no hi havia manera de substituir-la perquè anava molt trenada en l'obra, he deixat córrer lo de les sardanes» (Guimerà 1978: 1502). 


\subsubsection{La filla del mar (1900)}

\subsubsection{La nereide (1911)}

Fontana va donar a Trovati el llibret, que havia escrit, perquè el musiqués. És un drama líric en tres actes i, malgrat que el títol presenta una evocació mitològica, l'argument segueix de prop l'original català. Va estrenar-se a Nàpols el $1911 \mathrm{amb}$ poc èxit i aviat va desaparèixer de les cartelleres. ${ }^{50}$ En La filla del mar, la cançó, que el Pere Màrtir havia ensenyat a l'Àgata com a secret entre ells dos, és «La pastoreta», la qual en La nereide serà: «Due bacci, scolpiti in eterno, staranno dentro di me», la qual no es tracta de cap cançó popular italiana, sinó segurament és una cançó pseudopopular; per descomptat tampoc hi faltarà una «ària d'urlo» de l'Àgata. Els cors no hi tenen cap importància especial, ja que la musicalització es basa més en diàlegs cantats.

\subsubsection{Liebesketten (1912)}

Davant l'èxit de Tiefland, el 1908 d'Albert va dirigir-se de nou a Guimerà per demanar-li un altre drama i alhora va proposar-li de trobar-se a París, on per primera vegada, amb gran alegria del dramaturg català, van arribar a conèixer-se personalment. Després d'unes breus negociacions, el compositor alemany va adquirir els drets de La filla del mar (Raupp 1930: 222), la qual va musicar amb el títol de Liebesketten. Guimerà li havia proposat també La festa del blat o El fill del rei, posat que ja abans havia cedit els drets de La filla del mar a Fontana i Trovati, ara bé només per a Itàlia. Aquesta obra, com a teatre parlat, va conèixer el mateix èxit que Terra baixa amb María Guerrero com a l'Àgata; pel contrari, Liebesketten, ja a la seva estrena a Viena el 12 novembre del 1912, va fracassar.

L'òpera està situada en la Baixa Bretanya per comptes de la costa catalana iniciant-se amb un cor de pescadores, «Hinaus aufs Meer» (Cap a dins la mar). ${ }^{51}$ En Liebesketten, les àries és distribueixen de la següent manera: Balthasar, dues, Martin, dues, Sadika, cinc; al igual que la Marta, aquesta també ballarà, si bé de bon grat i frenèticament, acompanyada d'un solo de violí, campanetes i celesta com a reminiscència del seu origen oriental, bo i posant en relleu el seu caràcter salvatge. La cançó, que el Peter Martin va ensenyar a la Sadika com a senyal de complicitat, és aquí «ein Mädchen sass am Meeresstrand», la lletra de la qual es basa en la cançó popular catalana «El mariner» i no en «La pastoreta» com en el text de partida. Típic també de les òperes veristes són els cors i àries amb contingut religiós com a «preghiera», on s'exalta aquí l'actitud reverent dels pescadors. El final també difereix del text de partida, ja que, mentre que en La filla del mar, l'Àgata mata el Pere Màrtir amb la fitora i després se

${ }^{50}$ En l'actualitat la partitura de Trovati no existeix, ja que a causa dels bombardejaments de Milà en la segona guerra mondial l'arxiu complet de la casa Sonzogno va quedar completament destruït.

${ }^{51}$ Per a aquest cor va inspirar-se en la Cavalleria rusticana de Mascagni (Raupp 1930: 254). 
suïcida tirant-se al mar, en Liebesketten, el Noel tira un rampogoll per matar el Peter Martin, però la Sadika s'hi interposa morint ella en el seu lloc.

Tiefland, i amb menys grau, Liebesketten, són considerades encara avui dia com les obres principals del Verisme alemany (Zierau 1994: 183-186). Les crítiques de Liebesketten van atacar sobretot el llibret comentant que hi mancava la mà del poeta mentre que, per l'altra banda, van lloar «la finesa de la instrumentació, i el tractament magistral de l'orquestra» (Pangels 1981: 286-287), confirmant-se aquí de nou la importància del text sobre la música o almenys a nivell paritari a fi de formar un conjunt indestriable harmònic.

\section{BIBLIOGRAFIA}

Angermüller, R. (1976) «Zigeuner und Zigeunerisches in der Oper des 19. Jahrhunderts», Becker, H. (ed.) Die Couleur local in der Oper des 19. Jahrhunderts, Regensburg, Bosse, pp.131-159.

Aviñoa, X. (1985) La música i el modernisme, Barcelona, Curial.

Aviñoa, X. (1993) Una espina clavada al cor, Sitges, Ajuntament, (Quaderns de Sitges; 3 ).

Bacardit Santamaria, R. (2009) Tragèdia i drama en l'obra d'Àngel Guimerà, Barcelona, PAM.

Becker, H. (1976) «Die Couleur locale als Stilkategorie der Oper», Becker, Heinz (ed.) Die Couleur locale in der Oper des 19. Jahrhunderts, Regensburg, Bosse, pp. 23-45.

Becker, H. (ed., 1976) Die Couleur local in der Oper des 19. Jahrhunderts, Regensburg, Bosse.

Brown, C. S. (1984) «Theoretische Grundlagen zum Studium der Wechselverhältnisse zwischen Literatur und Musik», Scher, S. P. (ed.) Literatur und Musik, Berlin, E. Schmidt, pp. 28-39.

Cerdà Surroca, M. (1981) Els prerafaelites a Catalunya, Barcelona, Curial.

Curet, F. (1967) Història del teatre català, Barcelona, Aedos.

Fàbregas, X. (1971) Àngel Guimerà. Les dimensions d'un mite, Barcelona, Ed. 62.

Ferrier, P. + Tiercelin, L. (1907) La catalane, Paris, Choudens.

Gallén, E. (1986) «El teatre», Molas, J. (ed) Història de la literatura catalana. Vol. VIII, Barcelona, Ariel, pp. 379-448.

Gier, A. (ed., 1986) Oper als Text, Heidelberg, Winter.

Guimerà, À. (1975) Obres completes. Vol. I, Barcelona, Selecta.

Guimerà, À. (1978) Obres completes. Vol. 2, Barcelona, Selecta. 
Guimerà, À. (s. d.) Euda d'Uriach, doc. mecanografiat [signatura 83.115, de la Biblioteca de l'Institut del Teatre de Barcelona].

Istel, E. (1914) Das Libretto, Berlin, Schuster\&Loeffler.

Kaindl, K. (1995) Die Oper als Textgestalt. Perspektiven einer interdisziplinären Übersetzungswissenschaft, Tübingen, Stauffenberg.

Klotz, V. (1980) Bürgerliches Lachtheater, Reinbek, Rowohlt.

Link, K. (1975) Literarische Perspektiven des Opernlibrettos, Bonn, Bouvier.

Marfany, J. L. (1974) «Guimerà i el modernisme», Serra d'or, 180, pp. 573574.

Miracle, J. (1958) Guimerà, Barcelona, Aedos.

Neumann, P. (1999) Untersuchungen zu Werk und Rezeption des katalanischen Dramatikers Ângel Guimerà, Frankfurt, Lang.

Niemöller, K.-W. (1976) «Die kirchliche Szene», Becker, H. (ed.) Die Couleur local in der Oper des 19. Jahrhunderts, Regensburg, Bosse, pp. 341-369.

Ors, E. d'(1950) Obra completa catalana. Glosari 1906-1910, Barcelona, Selecta.

Pangels, C. (1981) Eugen d'Albert. Wunderpianist und Komponist. Eine Biographie, Zürich, Atlantis.

Raupp, W. (1930) Eugen d'Albert, Leipzig, Koehler\&Amelung.

Scher, S. P. (ed.) (1984) Literatur und Musik, Berlin, E. Schmidt.

Schueller, H. M. (1984) «Literature and Music As Sister Arts», Scher, S. P. (ed.) Literatur und Musik, Berlin, E. Schmidt, pp. 61-70.

Smith, P. J. (1970) The Tenth Muse. A Historical Study of the Opera Libretto, New York, Schirmer.

Soler, M. (1988) «Caciquisme i color local a Terra baixa d'Àngel Guimerà i a Tiefland de Rudolph Lothar i d'Eugen d'Albert», Zeitschrift für Katalanistik, 1, pp. 132-149.

Soler, M. (2005) «La dinàmica dramàtica de La filla del mar d'Àngel Guimerà i de Liebesketten de Rudolph Lothar i Eugen d'Albert: Una comparació», Zeitschrift für Katalanistik, 18, pp. 197-214.

Soler, M. (2007) «Dagoll Dagom y el musical Mar y cielo según Ángel Guimerá», Gestos, 22, 44, pp. 107-117.

Soler, M. (2007) «Dort, wo sich Himmel und Meer treffen», D. Dagom + X. Bru de Sala (eds.), Mar i cel-der Himmel und das Meer-, Trier, Matergloriosa Verl., pp. 7-11.

Soler, M. (2007) «Les adaptacions operístiques de Terra baixa d'Àngel Guimerà al francès (La catalane) i a l'alemany (Tiefland)», 20è Col-loqui Germano-Català, Tubinga, 23-26 febrer, Jané i Lligé, J. + Kabatek, J. (eds.) 
Fronteres entre l'universal i el particular en la literatura catalana, Aquisgrà, Shaker, pp. 25-44.

Soler, M. (2008) «"Les veles s'inflaran...": La musicalització de Mar i cel d'Àngel Guimerà per Dagoll Dagom i Xavier Bru de Sala», Stichomythia (rev. electr.), 7, pp. 123-135.

Soler, M. (2010) «El color local a La filla del mar d'Àngel Guimerà, a Liebesketten de Rudolph Lothar i Eugen d'Albert i a La nereide de Fernando Fontana i Ulisse Trovati», Zeitschrift für Katalanistik, 23, pp. 155-178.

Soler, M. (2012) «Un somni de festa modernista: La santa espina d'Àngel Guimerà», Zeitschrift für Katalanistik, 25, pp. 259-281.

Soler, M. (2012) «La influència de Somni d'una nit d'estiu de William Shakespeare en La santa espina d'Àngel Guimerà», Journal of Catalan Studies, $15,29-51$.

Zierau, U. (1994) Die veristische Oper in Deutschland, Frankfurt, Lang. 